\title{
A Paternidade na Percepção de Adolescentes de Classes Populares
}

Perceptions of Fatherhood Among Low Social Class Adolescents La Paternidad en la Percepción de Adolescentes de Clases Populares

Márcia Elisa Jager \& Ana Cristina Garcia Dias

Universidade Federal de Santa Maria

http://dx.doi.org/10.1590/1982-3703000382014 
Resumo: O objetivo deste estudo foi descrever como adolescentes homens de classes populares percebem a transição para a paternidade. Participaram do estudo três pais adolescentes de camadas populares, pais pela primeira vez de um bebê saudável. O instrumento utilizado para coleta de informações foi uma entrevista semiestruturada realizada em dois momentos: logo após o nascimento e aos seis meses de vida do bebê. Foi utilizado um delineamento de estudo de caso coletivo e longitudinal. Os principais resultados indicaram que os adolescentes perceberam a paternidade como uma experiência que trouxe amadurecimento e crescimento pessoal. Os adolescentes reconheceram suas responsabilidades de prover financeiramente a família e as responsabilidades ligadas ao cuidado do bebê. Eles ressaltaram a importância do apoio da família (pais), dos amigos e do trabalho para o bom desempenho do papel parental e no enfrentamento das responsabilidades paternas. A experiência de paternidade adolescente descrita neste estudo possivelmente está relacionada ao nível socioeconômico dos entrevistados, mas algumas de suas características podem ser comuns a pais adolescentes de outros contextos. Para uma compreensão adequada da paternidade na adolescência, é importante considerar o contexto de vida do adolescentes, uma vez que esta experiência é diretamente influenciada pelas suas condições sociais e econômicas, assim como pelo suporte familiar.

Palavras-chave: Paternidade. Adolescente.

Abstract: This study aimed to describe how low social class male adolescents perceive the transition to parenthood. Participants were three teenage fathers from low socioeconomic background and first-time fathers of a healthy baby. Data collection was performed using a semi-structured interview conducted at two time points: soon after the birth of the baby and when the baby was six-months-old. The research design was a longitudinal and collective case study. Main results indicated that adolescents perceived fatherhood as an experience that brings maturity and personal growth. The teenage fathers recognized their responsibility to provide financially to the family as well as to care for their child. Support from their parents, friends, and work was highlighted as an important factor for them to properly perform the parental role and undertake the new responsibilities. The experience of adolescent fatherhood described in this study is possibly related to the socioeconomic level of the adolescents interviewed; however, some of its characteristics may be common to adolescent fathers from other socioeconomic backgrounds. For an adequate understanding of fatherhood during adolescence, it is important to consider the adolescent life context, as this experience is directly influenced by their social and economic conditions as well as family support.

Keywords: Paternity. Adolescent.

Resumen: El objetivo de este estudio fue describir cómo los adolescentes varones de clase social baja, perciben la transición a la paternidad. Los participantes fueron tres padres adolescentes de bajo nivel socioeconómico, padres por primera vez de un bebé sano. El instrumento utilizado para la recolección de datos fue una entrevista semi-estructurada realizada en dos ocasiones: poco después del nacimiento del bebé, y cuando el bebé tenía seis meses de edad. El diseño de la investigación fue un estudio longitudinal de casos múltiples. Los resultados principales indicaron que los adolescentes perciben la paternidad como una experiencia que trae la madurez y el crecimiento personal. Los adolescentes reconocieron su responsabilidad de proveer económicamente a la familia, así como las responsabilidades del cuidado del bebé. El apoyo de los padres, amigos y entorno de trabajo se destacó como un factor importante para que puedan desempeñar bien el papel de padres y para enfrentar a las nuevas responsabilidades. La experiencia de la paternidad adolescente descrita en este estudio es posiblemente relacionada con el nivel socioeconómico de los adolescentes entrevistados, pero algunas de sus características pueden ser comunes a padres adolescentes de otros niveles socioeconómicos. Para una adecuada comprensión de la paternidad en la adolescencia, es importante tener en cuenta el contexto de vida de los adolescentes, ya que esta experiencia es directamente influenciada por sus condiciones sociales y económicas, así como por el apoyo familiar.

Palabras-clave: Paternidad. Adolescente. 
A paternidade durante a adolescência gera transformações na identidade e (re) configura os vínculos afetivos do adolescente que assume a condição de pai (Gomes, 2006, Meincke et al., 2011). Essas mudanças são decorrentes, principalmente, da transição nos papéis sociais que o adolescente vivencia a partir do nascimento do filho. O papel social do adolescente na sociedade contemporânea implica, predominantemente, nas ideias de escolarização, diversão e planejamento profissional, enquanto o papel paterno demanda amadurecimento pessoal, social, estilo de vida responsável e envolve o papel de provedor econômico (Dias \& Aquino, 2006; Gomes, 2006; Gonçalves \& Knauth, 2006; Meincke et al., 2011).

Os papéis sociais são definidos em um contexto histórico, cultural e social (macrossistema) (Bronfenbrenner, 2002; Bronfenbrenner, Carvalho-Barreto, 2011). As mudanças nos papéis sociais que ocorrem durante o ciclo vital são compreendidas por Bronfenbrenner (2002) como transições ecológicas. As transições ecológicas alteram a forma de agir, pensar e sentir das pessoas para que o comportamento corresponda às expectativas socialmente esperadas para um determinado papel social. A possibilidade de o sujeito desempenhar satisfatoriamente um determinado papel social irá depender das relações interpessoais, das exigências envolvidas no desempenho do papel presentes nos diferentes ambientes do qual faz parte e do apoio recebido de pessoas com as quais o indivíduo mantém relações duradouras (Bronfenbrenner, 2002).

Nesta perspectiva, compreende-se que a paternidade é permeada pela maneira como o adolescente vivencia sua transição ecológica, bem como pelo apoio recebido e pelas características e relações estabelecidas nos diferentes ambientes do qual faz parte. Esses fatores influenciam na percepção da vivência da paternidade durante a adolescência, fazendo com que essa experiência não seja percebida pelo adolescente como necessariamente ruim e/ou prejudicial ao seu desenvolvimento (Bueno, Meincke, Schwartz, Soares, \& Corrêa, 2012;
Costa et al., 2005; Dias \& Aquino, 2006; Heilborn \& Cabral, 2006; Levandowski \& Piccinini, 2006; Meincke et al., 2011; Orlandi \& Tonelli, 2008). De fato, isso pode ocorrer especialmente em contextos populares nos quais a transição de um papel social a outro pode estar associada ao amadurecimento e ao desenvolvimento de responsabilidade do jovem que se torna pai "precocemente" e a uma menor exposição a determinados fatores de riscos presentes nesses ambientes. É frequente que, nas trajetórias dos jovens pobres, especialmente, esteja presente uma obrigação moral que faz com que estes adolescentes assumam a função de provedor e se responsabilizem pela família, apesar de sua pouca idade (Heilborn \& Cabral, 2006). Isso tende a não ocorrer no contexto da classe econômica média ou alta, uma vez que nem sempre estes adolescentes se sentem responsáveis pelo provimento da nova família, já que, comumente, recebem de suas famílias de origem um auxílio financeiro (parcial ou total) para o cuidado e sustento do filho. Neste contexto econômico, a paternidade na adolescência tende a não implicar em um "encurtamento" da juventude, uma vez que a família de origem, frequentemente, assume algumas responsabilidades que seriam do jovem, o "libertando" para a vivência da adolescência e para o planejamento futuro referente à escolarização e profissionalização, frequentemente amplo e com possibilidades reais de concretização (Heilborn, 2006).

Para Bustamante (2005) e Hardy (2007), a responsabilização econômica pela "nova" família, comum em adolescentes de classes populares, é um aspecto que recebe destaque, uma vez que é nesta função social que a significação da masculinidade se concretiza. Neste contexto no qual poucas oportunidades futuras se fazem presentes, ser pai e provedor de uma família podem oferecer um prestígio social que, dificilmente, seria atingido através de outras formas (escolarização e profissionalização qualificada) em virtude da violência estrutural (Boulding, 1981) a qual os jovens pobres (meninos e meninas) são submetidos (Bustamante, 2005; Hardy, 2007). 
Aliás, a significação social por meio da parentalidade em adolescentes de classes populares acontece também com as meninas. É através da maternidade que meninas de classes populares encontram um reconhecimento, uma vez que ser mãe neste contexto é mais valorizado socialmente do que em outras classes sociais, pelos mesmos motivos citados acima. Nestes contextos, o amadurecimento pessoal e responsabilização da menina também ocorrem, representando a possibilidade de uma vivência parental positiva, especialmente na presença de apoio familiar e social, tal qual como ocorre com os meninos (Patias, Jager, Fiorin, \& Dias, 2011; 2012; Gontijo \& Medeiros, 2008; Levandowski, Piccinini, \& Lopes, 2008).

Descrever como adolescentes de classes populares vivenciam a experiência da paternidade oferece possibilidades para identificar as necessidades e demandas específicas desta população. A partir da identificação destas demandas, as políticas públicas podem direcionar estratégias de intervenções a fim de qualificar e potencializar as práticas de saúde direcionadas a esses adolescentes. Desta forma, a equidade de gênero, marco das práticas em saúde, poderá concretizar-se. Ademais, é importante dizer que essa necessidade não se restringe somente aos pais de classes populares, uma vez que a paternidade, de forma geral, vem sendo negligenciada pelas políticas públicas (Bustamante, 2005).

Conforme os pressupostos da teoria bioecológica do desenvolvimento humano (Bronfenbrenner \& Carvalho-Barreto, 2011), a influência de fatores contextuais pode deslocar a ideia de incapacidade e imaturidade do adolescente para assumir responsabilidades paternas para uma ideia de paternidade responsável. Isto é possível na medida em que os adolescentes são investidos, amparados e apoiados familiar e socialmente (Carvalho, Merighi, \& Jesus, 2009). Neste sentido, o objetivo deste estudo é compreender como adolescentes de classes populares percebem a transição para a paternidade. Estes resultados podem facilitar a identificação da rede de apoio disponível e as variáveis que auxiliam na transição do papel social de "adolescente" para "pai".

\section{Método}

\section{Participantes}

Participaram do estudo três pais com até 20 anos de idade, pertencentes a estratos populares e que estavam sendo pais pela primeira vez de um bebê saudável. O critério etário utilizado para a definição do período da adolescência foi o da Organização Mundial de Saúde (10 aos 19 anos de idade) (WHO, 2013). Entretanto, também participaram do estudo pais que haviam completado, recentemente, 20 anos de idade. Embora o critério etário funcione como uma importante referência, a ideia de que o jovem, ao completar 20 anos não seria mais um adolescente deve ser relativizada (Neri, 2001).

Os pais foram selecionados do grupo de participantes da pesquisa "Paternidade adolescente e a relação pai-bebê no primeiro ano de vida da criança (Jager \& Dias, 2012a). Este estudo longitudinal acompanhou um grupo de cinco pais adolescentes. O estudo buscou compreender a vivência da paternidade e o envolvimento paterno em práticas de cuidados ao bebê pequeno em três momentos: fase I (até 40 dias após o nascimento do bebê); fase II (sexto mês de vida do bebê) e fase III (um ano de vida da criança).

\section{Instrumentos, Delineamento e Procedimentos}

O estudo longitudinal construído por Jager e Dias (2012a) utilizou uma ficha de triagem para identificar os critérios de inclusão dos participantes, uma ficha de dados socioeconômicos e culturais para caracterizá-los e duas entrevistas semiestruturadas (paternidade e práticas de cuidados) para investigar as questões do estudo. O instrumento utilizado neste estudo foi a entrevista sobre a experiência da paternidade. Esta entrevista foi aplicada na fase I e ll e teve como objetivo investigar como os adolescentes percebiam a transição para a paternidade, as responsabilidades assumidas e a influência das relações desenvolvidas na família, grupo de amigos e trabalho nesta experiência. Estes focos investigativos foram definidos de acordo com os pressupostos 
da teoria bioecológica do desenvolvimento humano. Esta teoria trabalha a ideia de que as relações interpessoais (processo proximal) desenvolvidas nos diferentes contextos dos quais o sujeito faz parte influenciam na vivência de experiências e no seu desenvolvimento humano, como um todo (Bronfenbrenner \& Carvalho-Barreto, 2011).

Foi utilizado um delineamento de estudo de caso coletivo (Stake, 1994) e longitudinal (Anstey \& Hofer, 2004), dando atenção às particularidades e semelhanças entre os resultados encontrados. O processo de seleção dos participantes ocorreu através do preenchimento de uma ficha de triagem com dados de critérios de inclusão para o estudo. A seleção dos participantes ocorreu durante o período de janeiro à março de 2013 em dois hospitais públicos de uma cidade do interior do Estado do Rio Grande do Sul. O preenchimento das fichas ocorreu durante a realização do teste da orelhina e através do levantamento de dados em fichas de parturientes em prontuários disponibilizados pelos hospitais que colaboraram com a pesquisa. Na realização do teste da orelhina, antes de iniciar os exames, o responsável que estava com o bebê foi convidado e auxiliado pela pesquisadora responsável no preenchimento da ficha em uma sala reservada. No levantamento de dados realizado por intermédio da ficha da parturiente, a pesquisadora responsável identificou e registrou as informações solicitadas na ficha de triagem. Os casos que atendiam aos critérios de inclusão do estudo foram contatados e convidados para a participação na pesquisa.

Para participar do estudo os pais deveriam, no momento do primeiro contato, ter até 20 anos de idade, ser pai (biológico) pela primeira vez de um bebê saudável, estar em um relacionamento amoroso com a mãe do bebê, pertencer à classe econômica $\mathrm{D}$ ou $\mathrm{E}$ (renda familiar até R\$1.126,00) (Neri, 2010) e aceitar participar voluntariamente do estudo. Estes critérios de inclusão permitiram a identificação de sete pais adolescentes. A primeira entrevista (fase I) aconteceu em local cedido pelo hospital em dia e hora apropriados ao participante. A segunda entrevista (fase II) foi realizada com cinco pais adolescentes, uma vez que dois deles desistiram de colaborar com o estudo. As entrevistas da fase II ocorreram nas residências dos adolescentes. As entrevistas foram realizadas pela pesquisadora responsável pelo estudo, tiveram duração de, em média, uma hora e trinta minutos e utilizou-se como recurso de apoio um gravador. Todas as entrevistas foram transcritas e, após análise de informações, apagadas na íntegra.

Dos cinco pais que participaram da fase I e II da pesquisa, selecionaram-se três adolescentes para a realização deste estudo, conforme o seguinte critério: a oferta de informações completas e ricas em significados (ausência de respostas lacônicas, tais como: "bom"; "mais ou menos"; "não sei explicar"; "normal"). Destaca-se que este estudo foi aprovado pelo comitê de ética da Universidade Federal no qual está vinculado, conforme parecer $n^{\circ} 148.671$. Os nomes dos participantes são fictícios.

\section{Análise das Informações}

As informações foram analisadas coletivamente, de forma qualitativa. A análise de informações, na pesquisa qualitativa, é um processo não matemático e de interpretação. O objetivo é descobrir conceitos e relações das informações brutas e de organizar esses conceitos de forma sistemática em um esquema explanatório teórico (Strauss \& Corbin, 2008). Realizou-se também uma análise longitudinal dos casos, uma vez que se procurou identificar a evolução na forma de pensar dos participantes em mais de um momento de coleta de informações (Anstey \& Hofer, 2004).

A apresentação dos resultados contempla a descrição dos casos nos dois momentos da coleta de informações e, posteriormente, a análise qualitativa das semelhanças e particularidades encontrada nos casos, conforme sugere Stake (1994). A análise é realizada pelo viés da análise de conteúdo temática (Bardin, 2006). Esta técnica é uma sequência de atividades a serem desenvolvidas que se resume na leitura das informações coletadas na pesquisa, categorização e interpretação. 
O tema, enquanto unidade de registro, é utilizado para estudar motivações, opiniões, atitudes, valores, crenças, tendências, etc. As entrevistas individuais ou de grupo, abertas ou semiestruturadas podem ser analisadas tendo o tema como base (Bardin, 2006). Os temas de análises criados para este estudo foram: Transição para a paternidade; Responsabilidades Assumidas; Relações familiares; Grupo de amigos; e Trabalho. Em todos os temas de análise, é oferecido destaque às semelhanças e particularidades encontradas entre os casos analisados. As semelhanças são compreendidas como as experiências e/ou percepções trazidas por dois ou três participantes do estudo. Já as particularidades são compreendidas como as opiniões de um participante que trouxe experiências e/ou percepções diferentes dos demais.

A base teórica utilizada para a discussão dos casos foi a teoria bioecológica do desenvolvimento humano (Bronfenbrenner, 2002; Bronfenbrenner \& Carvalho-Barreto, 2011). Esta teoria ofereceu suporte para o desenvolvimento integral deste estudo, uma vez que direcionou a construção dos focos investigativos da entrevista, formação das categorias de análise e discussão das informações.

\section{Resultados}

CASO 1 - Pedro (20 anos), companheiro de Joana (18 anos). Pai de Morgana. Atualmente trabalha como açougueiro em um supermercado próximo de sua casa. Durante os primeiros seis meses de vida do bebê, o casal coabitou com a família de Pedro (pais e tios).

Período de até 40 dias após o Nascimento do Bebê: Pedro descreveu que "não planejava ser pai agora [...] essa idade era de sair, fazer coisa de jovem mesmo". Entretanto, ele reconheceu o aumento da responsabilidade, principalmente financeira. Ele acrescentou mudanças na rotina: "agora não dá mais pra fica saindo, tem que cuida dela" e a possibilidade de (re) planejamento: "é outra coisa, sou outra pessoa, outro foco [...] minha rotina e prioridades mudaram [...] é quase só do trabalho pra casa". A mãe de Pedro (pai já faleceu) foi uma figura importante para o enfrentamento das mudanças decorrentes da paternidade, pois "sempre quando eu precisei ela tava junto". Com a paternidade e o nascimento do bebê, a mãe serviu como um apoio e referência nos cuidados à criança: "a gente sempre apela pra ela quando a Morgana tá chorando e a gente não sabe o que fazer". Com a paternidade, o grupo de amigos foi substituído por pessoas adultas e maduras: "o meu grupo de amigos de agora, é mais de casais... a gente joga bola e churrasco, se reúne assim, mais caseiro". O afastamento dos amigos antigos aconteceu "porque a gente teve que cresce rápido entendeu, e ai eles continuam naquela vida que eu era antes, faze festa e tal...". Pedro trabalhava oito horas diárias e almoçava no trabalho. Ele ainda afirmou que chegar em casa depois de um mau dia de trabalho influenciava no seu humor: "fico na minha, não chego muito perto da Morgana e nem converso muito com a Joana". Ele ainda acrescentou que o tempo despendido no trabalho prejudicava o tempo disponível para o convívio com a filha e com a companheira.

Seis Meses após o Nascimento do Bebê: Pedro ainda reconheceu a experiência da paternidade como precoce, mas descreveu que "está gostando de ser pai". A paternidade representou a aquisição de responsabilidades, predominantemente financeiras: "Como eu disse da primeira vez, é cuidar deles, não deixar faltar nada". Pedro reafirmou que a paternidade trouxe mudanças pessoais, familiares e sociais: "sou outra pessoa, tenho outro estilo de vida [...] é tudo em função dela [...] a gente não sai mais como antes". Pedro ainda acreditava que seu principal papel era o de provedor. As relações familiares de Pedro se fortaleceram nestes seis meses de vida do bebê, pois "a mãe ta sempre perto, ajudando e orientando, a gente conversa mais, a Morgana uniu mais". Outras pessoas da família também ajudaram a cuidar do bebê, quando necessário. $\mathrm{O}$ grupo de amigos de Pedro permaneceu os mesmos de seis meses atrás: "a maioria tem filho também, faz um joguinho, um churrasco, as mulher vem junto, dá pra conversa, tira as dúvidas, a gente fica falando da mulher da 
gente (risos), dos problemas de casa, com os filhos... é bom". Sobre o trabalho, Pedro disse que é "chefe de setor do açougue" $\mathrm{e}$ "o salário mudo bastante". Ele verbaliza que isso influenciou na tranquilidade financeira da família, aumentando seu senso de segurança enquanto provedor familiar. Pedro admitiu que situações estressantes do dia a dia de trabalho influenciavam em suas relações familiares: "eu fico bem quieto... se alguém fala alguma coisa daí eu já me altero um pouco... eu me afasto um pouco da Morgana e da Joana". Ele permaneceu com a opinião de que o tempo dispensado no trabalho limitava o tempo de convivência familiar.

CASO 2 - Fernando (19 anos), militar (Exército Brasileiro), pai de Michel. Fernando não coabitava com a companheira, Alana (16 anos), mas, no período de até 40 dias após o nascimento do bebê, o casal mantinha um relacionamento estável. Este relacionamento não se estendeu até os seis meses de vida do bebê. Alana e o bebê moram na casa da família de Alana.

\section{Período de até 40 dias após o Nascimento do}

Bebê: Fernando destacou que "não podia ser pai adolescente, minha criação não era pra isso". Ele evidenciou que o foco deveria ser no "futuro profissional e estabilidade financeira". Fernando demorou a reconhecer a paternidade, pois "desconfiava dela, me traia". Próximo ao nascimento do bebê, através de um exame de DNA, reconheceu a paternidade e admitiu a aquisição de crescimento e amadurecimento pessoal. Ele ainda acrescentou que "minhas prioridades mudaram, agora é tudo pensando nela, meu dia é em função dela [...] antes não era assim, não tinha responsabilidade nenhuma, tinha muito mais liberdade pra faze o que eu queria". Sua principal responsabilidade era "não deixar faltar nada pra eles dois. Tanto com remédio, alimentação, tudo". Sua relação com Michel era "diferente". Os pais de Fernando desempenharam um importante papel para que ele assumisse suas responsabilidades: Fernando contou que seus pais "são rígidos nas responsabilidades assumidas, o filho é meu e vou criar como tem que ser, não deixando falta nada, desde o dinheiro até o amor". Fernando relatou que com a paternidade "não perdi amigos, mas também não ganhei". Isto porque as atividades no grupo de amigos consistiam em brincadeiras "de gente velha" e situações que puderam ser estendidas e compartilhadas com a experiência de ser pai: "Enquanto uns vão pra noite, bebem e fazem farra, a gente fazia isso. Juntava 10, 15 piá pra fazer pão com molho, salsicha, toma refri, essas coisas assim... mas agora não é mais tão frequente". Os amigos apoiaram Fernando na descoberta da gravidez e isto o surpreendeu, pois "a gente sempre acho lambada um cara te filho antes de ta estabilizado financeiramente... mas não, eles me apoiaram... isso foi importante pra mim". Fernando reconheceu que "o tempo em casa é curto" e que "ouvi um monte de coisa no trabalho e lida com situações difíceis no quartel" influenciou no seu humor e, portanto, na relação com Alana ou com qualquer outra pessoa próxima. Entretanto, ele reconheceu o trabalho como principal meio para cumprir seu papel e demonstrou receio de não conseguir prover financeiramente sua família.

Seis Meses após o Nascimento do Bebê: Fernando não mantinha mais um relacionamento amoroso com Alana. O casal procurou o recurso judicial de guarda compartilhada. Na época da realização da entrevista, Michel ficava com o pai "no final de semana e algumas vezes por semana". Fernando relatou que "não queria ser pai tão novo", mas que no momento, "amo ele mais do que qualquer coisa [...] sou outra pessoa". As preocupações referentes a "não deixa faltar nada" permaneceram. Fernando não pagava pensão para Michel, pois "ela e a mãe dela conversaram e optaram que ao invés da pensão, eu dou as coisas, roupa, comida, fralda, leite...". Os pais de Fernando continuavam auxiliando no seu desempenho paterno. Michel aproximou as relações familiares: "eu sempre tive o apoio do meu pai e da minha mãe... sempre que ele vem com uma necessidade diferente eles me ajudavam". O grupo de amigos de Fernando não sofreu alterações durante os seis primeiros meses de vida de Michel: "como não sou de sair, de festa e bebe, a gente faz coisa de gente velha mesmo, olha um filme em casa, fazer uma coisa pra comer". Fernando reconheceu que a carga horária do trabalho e o estresse laboral continuaram atrapalhando seu convívio com Michel: "eu passo mais tempo lá no quartel do que em 
casa". Quando chegava em casa após um dia estressante, Fernando relatou que "medo de passar alguma coisa ruim pra ele... daí eu tomo um banho bem demorado, do uma caminhada e depois pego ele".

CASO 3 - Henrique (20 anos), eletricista, companheiro de Marília (16 anos), pai de Eduardo. Durante os primeiros seis meses após o nascimento do bebê, o casal coabitou com a família de Marília.

Período de até 40 dias após o Nascimento do Bebê: Henrique destacou que a experiência da paternidade "não era pra ser agora, porque essa idade era de aproveitar a vida". Entretanto admitiu que ser pai trouxe responsabilidade (predominantemente financeira), amadurecimento e o fez "virar homem de verdade [...] não fico mais zoando por ai, sem compromisso". As relações familiares (família de origem) de Henrique não foram boas, uma vez que sofreu violência e viveu em condições de vida insalubres. Esta história de vida fez com que ele ficasse satisfeito com a notícia da paternidade, pois poderia "fazer com seu filho tudo diferente". Sua principal preocupação era não deixar faltar nada para o filho e para Marília, para que eles "não tenham a vida que eu tive". A família de Henrique não representava apoio ou referência de modelo a ser seguido. Ele atribuiu "muito sofrimento" à relação com seus pais. Com o relacionamento amoroso e a gestação, houve um afastamento do grupo de amigos, pois "a gente fica querendo coisas diferentes, antes era festa, bebida e diversão, agora não, é mais responsabilidade". Na época da entrevista, Henrique considerou como amigos a sua companheira, sua mãe, sua sogra e seu patrão, pois "apóiam quando eu preciso e estão do meu lado nas dificuldades". Henrique trabaIhava oito horas diárias como eletricista e não voltava para casa ao meio dia. A carga horária de trabalho e as preocupações do ambiente de trabalho afetavam a qualidade das relações familiares: "às vezes a gente vem com a cabeça meio estressada... as vezes a gente se estressa com as pessoa em casa, usa as palavra que não deve, mas quando eu chego eu sempre procuro não fazer isso." Ele admitiu que o trabalho auxiliava no cumprimento de suas responsabilidades financeiras. Ele se preocupava com a estabilidade e busca melhores oportunidades para poder oferecer boas condições financeiras à sua família.

Seis Meses após o Nascimento do Bebê: Henrique relatou que "o Eduardo enche aquele vazio todo que tinha, aquele sofrimento todo que passei" e que, "apesar de ser pai novo", a experiência de convivência com o filho estava sendo positiva. A preocupação referente ao sustento familiar permaneceu. O nascimento de Eduardo não aproximou as relações familiares de Henrique. Este afastamento sempre existiu e o sentimento de tristeza decorrente de relações familiares "doentes" fizeram com que ele desejasse "uma relação de muito amor com Eduardo". Henrique via a sua mãe esporadicamente e possuía contato distante com seus irmãos: "eles estando ou não estando aqui não faz diferença, aliás, até acho melhor não estarem mesmo". Henrique tinha um relacionamento positivo com a família de Marília, pois "agora eles viram que a gente não é irresponsável". Ele descreveu que "a família dela agora me enxerga como um pai excelente, eles me tratam com mais respeito". Seu grupo de amigos, na época da entrevista, eram os colegas de trabalho. Henrique admitiu que com os amigos mais velhos, casados e com família "dá pra gente conversa sobre filho, família, essas coisas [...] um momento pra gente busca referência". Henrique permaneceu no emprego e o chefe continuou representando uma figura importante. O chefe auxiliava financeiramente "no rancho, roupa, no que precisa" e na flexibilidade de horários quando ele precisa atender as necessidades do filho. Henrique permaneceu com as preocupações sobre estabilidade financeira da família e de sua função enquanto provedor, colocando seu trabalho em um lugar de destaque.

\section{Discussão}

\section{Transição para a Paternidade}

\section{Semelhanças}

Durante o período investigado, os adolescentes perceberam a paternidade como uma experiência imprópria para a idade, uma 
vez que a adolescência era um período no qual se deveria "fazer coisa de gente jovem", "pensar no futuro profissional" e "aproveitar a vida". Resultados semelhantes são comuns em estudos com pais adolescentes (ambos os sexos) (Carvalho, Merighi, \& Jesus, 2009; Gomes, 2006; Hoga \& Reberte, 2009; Venturini, 2010). Esta maneira de perceber a adolescência como um período socialmente adequado para a diversão, desenvolvimento pessoal e profissional (Carvalho, Merighi, \& Jesus, 2009; Heilborn \& Cabral, 2006) é alicerçado em valores do macrossistema transmitidos através de crenças e comportamentos transgeracionais desenvolvidos pelos diferentes contextos nos quais $\mathrm{O}$ indivíduo está inserido, tais como: família, escola, igreja, trabalho e órgãos do governo (Bronfenbrenner \& Carbalho-Barreto, 2011). Estes valores podem indicar que ocorrência da gestação e a vivência da parentalidade são impróprias para a adolescência, uma vez que a responsabilidade adquirida pode dificultar a realização de outras atividades consideradas socialmente como "próprias da idade" (Heilborn \& Cabral, 2006). Isto pode justificar a crença sobre a vivência da paternidade durante a adolescência apresentada pelos participantes deste estudo.

Entretanto, os participantes atribuíram significados positivos à paternidade, tais como o aumento de responsabilidade e indicaram algumas mudanças sociais (alteração na rotina/perda da liberdade) que representaram amadurecimento e crescimento pessoal. Estes ganhos compensaram a perda de liberdade e alterações na rotina dos participantes. Resultados semelhantes podem ser encontrados em pesquisas realizadas com pais adolescentes, especialmente os de classes populares (Carvalho, Merighi, \& Jesus, 2009; Costa et al., 2005; Heilborn \& Cabral, 2006; Hoga \& Reberte, 2009; Meincke et al., 2011; Orlandi \& Toneli, 2008; Venturini, 2010).

O nascimento do filho representou para os adolescentes participantes desta pesquisa uma transição ecológica (mudança de papel social - adolescente X pai). A colocação de uma pessoa em um papel social tende a evocar comportamentos, pensamentos, sentimentos, percepções, atividades e padrões de relação interpessoal consistentes com as expectativas associadas àquele papel, definidas em nível de macrossistema (Bronfenbrenner, 2002; Bronfenbrenner \& Carvalho-Barreto, 2011). Socialmente e historicamente, ser pai implica em ser responsável e maduro, uma vez que o nascimento da criança e a formação de uma família representam uma inserção no mundo adulto e uma readaptação nos projetos e estilo de vida (Dias \& Aquino, 2006; Gomes, 2006; Heilborn \& Cabral, 2006). Estes aspectos puderam ser observados também no discurso dos adolescentes deste estudo, evidenciando que os participantes pareciam estar conseguindo transitar entre os dois papéis sociais vividos (adolescente e pai), percebendo a paternidade de forma responsável e buscando adequar-se ao que era esperado deles.

\section{Particularidades}

Um dos adolescentes (Caso 3) percebeu a paternidade como uma oportunidade para (re) significar sua vida e relações afetivas. As relações familiares (família de origem) anteriores deste adolescente foram caracterizadas por vínculos afetivos frágeis e vulneráveis e isto o motivou a "fazer diferente". A maneira de perceber o filho como uma possibilidade de preencher um vazio e (re) significar experiências anteriores é comum em situações de vulnerabilidades familiares (Brazelton \& Cramer, 2002; Gomes, 2006; Lamb, 1997). No contexto de relações familiares conflituosas, o adolescente pode se encontrar sem marcos referenciais e passar a idealizar a construção de sua própria família, mais equilibrada (Gomes, 2006), como pode ser observado neste caso particular.

As experiências familiares anteriores (vínculos interpessoais construídos em nível de microssistema) retratam influências do cronossistema (aspectos transgeracionais) no comportamento e crenças atuais de um indivíduo. Estas influências podem ser negativas ou positivas e estão relacionadas à maneira como o indivíduo viveu estas experiências familiares e quais as consequências que elas geraram. Eventos e experiências anteriores comumente servem de estímulos para mudanças no 
comportamento/desenvolvimento humano (Bronfenbrenner \& Carvalho-Barreto, 2011; Bronfenbrenner \& Morris, 1998). No caso do adolescente participante deste estudo, as experiências pessoais e familiares negativas o motivaram para proporcionar um ambiente familiar melhor para seu filho. Isto pode ser observado também em mães adolescentes (Santos \& Carvalho, 2006; Santos \& Nogueira, 2009). De fato, a possibilidade de livrar-se de frustrações e desamparos do passado por meio da criação de um relacionamento novo é um dos maiores incentivos para se ter e criar um filho (Brazelton \& Cramer, 2002).

\section{Responsabilidades Assumidas}

\section{Semelhanças}

As principais responsabilidades descritas pelos participantes estiveram ligadas ao papel social do homem e da mulher. Os adolescentes demonstraram preocupações relacionadas ao desenvolvimento e futuro do filho, mas o cuidado e a educação foram de responsabilidade predominantemente feminina. A preocupação financeira é frequentemente citada pelos pais em estudos sobre a experiência da paternidade (Bornholdt, Wagner, \& Staudt, 2007; Freitas et al., 2009 Gabriel $\&$ Dias, 2011).

As responsabilidades parentais são definidas pelos papéis sociais de homem e mulher (Heilborn \& Cabral, 2006; Parke, 1996), determinados em um nível de macrossistema (Bronfenbrenner, 2002; Bronfenbrenner \& Carvalho-Barreto, 2011). No que se refere especialmente aos homens, a tendência histórica que coloca o pai como principal fonte de sustento da casa e da família explica seu papel social ligado à função de provedor (Bornholdt, Wagner, \& Staudt, 2007; Freitas et al., 2009; Lamb, 1997). O macrossistema (estereótipos culturais e sociais) influencia a maneira pela qual uma pessoa se comporta em uma determinada situação, as atividades nas quais ela se engaja e as relações que estabelecem com as pessoas presentes no seu ambiente (Bronfenbrenner, 2002). Neste sentido, apesar de os papéis familiares contemporâneos demonstrarem maior equidade nas responsabilidades parentais, ainda é esperado que o homem (adolescente ou não) assuma responsabilidades financeiras e a mulher as responsabilidades pela educação e pelo cuidado dos filhos (Dias \& Aquino, 2006, Freitas et al., 2009; Piccinini, Silva, Gonçalves, Lopes, \& Tudge, 2004).

Através da função de provedor, os adolescentes deste estudo preocuparam-se em oferecer condições favoráveis ao desenvolvimento do bebê, indicando um reconhecimento de suas responsabilidades paternas, ainda ligadas a uma noção predominantemente tradicional da paternidade (Ramires, 1997). No discurso dos adolescentes não foram detectadas particularidades sobre as responsabilidades assumidas.

\section{Relações Familiares}

\section{Semelhanças}

Os pais de dois adolescentes (Caso 1 e 2) participantes deste estudo representavam apoio e modelo para o desempenho do papel paterno (cuidado ao bebê e responsabilidades financeiras). É comum que a família do adolescente represente uma importante rede de apoio para o exercício da paternidade (Carvalho, Merighi, \& Jesus, 2009; Lamb \& Elster, 1986). O apoio familiar oferecido pode ser de origem psicológica/emocional (modelos, conselhos, ajuda nos cuidados) e/ou instrumental/financeira (auxilio no cuidado e sustento da criança) (Bueno et al., 2012; Dias \& Aquino, 2006; Heilborn \& Cabral, 2006; Nogueira, Martins, Schall, \& Modena, 2011). A percepção da família como rede de apoio é resultado das relações que o adolescente estabelece no microssistema (Bueno et al., 2012). Neste sentido, quanto mais positivas forem as relações familiares, maiores serão as possibilidades de o indivíduo perceber sua família como um apoio para os momentos de dificuldades (Bronfenbrenner e Carvalho-Barreto, 2011).

Nos cuidados com o bebê, a principal figura de referência para o adolescente foi a mulher (mãe do adolescente ou do bebê). Cuidar de um filho continua sendo uma atribuição feminina, permanecendo uma naturalização da maternidade e um estranhamento 
da paternidade, principalmente quando se trata de questões referentes ao cuidado e à educação dos filhos (Dias \& Aquino, 2006; Freitas et al., 2009). Neste sentido, a mãe serve como modelo e referência aos jovens na transmissão de conhecimentos uma vez que, social e historicamente, é da mulher a habilidade de cuidado (Bornholdt, Wagner, \& Staudt, 2007; Carvalho, Mereghi, \& Jesus, 2009; Levandowski \& Piccinini, 2006; Piccinini et al., 2004). O modelo materno (ou de outro cuidador) é importante na medida em que o desempenho do indivíduo em determinada tarefa e/ou comportamento é reforçado se outra pessoa oferecer um exemplo de conduta e direcionamentos sobre a prática (Bronfenbrenner e Carvalho-Barreto, 2011). Neste sentido, a mãe apareceu como figura importante que modelou e ofereceu referência para o adolescente se constituir enquanto pai e assumir algumas responsabilidades no cuidado ao bebê.

\section{Particularidades}

Um dos adolescentes (Caso 03) não percebeu a família de origem como um apoio para a vivência da paternidade, uma vez que ele atribuiu sofrimento e destacou vínculos afetivos fragilizados às suas experiências familiares anteriores. Suas relações familiares, na época da entrevista, se concentravam em pessoas que faziam parte da família da companheira e o apoio foi oferecido, principalmente, por amigos e colegas de trabalho. São frequentes os estudos que citam a família de origem do adolescente como importante rede de apoio psicológico e financeiro (Bueno et al., 2012; Dias \& Aquino, 2006). Com o adolescente participante deste estudo, isto não foi observado e o apoio para enfrentar a transição da paternidade foi construído a partir das relações estabelecidas em outros ambientes do qual o adolescente fazia parte (trabalho e grupo de amigos). Isto indica características do mesossistema sobre a vivência da paternidade. A ligação entre diferentes ambientes, nos quais o indivíduo constrói relações duradouras, amplia sua rede social e proporciona a aquisição de apoio e de referências para a aquisição e manutenção de comportamentos (Bronfenbrenner e Carvalho-Barreto, 2011).
As relações que este adolescente desenvolveu com os familiares da companheira foram intensificadas na medida em que o casal demonstrou capacidade para cuidar da criança. As opiniões dos familiares da companheira sobre a habilidade parental do casal estavam alicerçadas na crença da irresponsabilidade e incapacidade de um adolescente cuidar de um bebê. Estas crenças familiares revelam influências do macrossistema (Bronfenbrenner, 2002; Bronfenbrenner e Carvalho-Barreto, 2011) sobre a maneira de perceber a maternidade/paternidade durante a adolescência, já discutidas no primeiro eixo temático deste estudo.

A crença de que pais adolescentes teriam o exercício da maternidade/paternidade prejudicada por limitações características do período de maturação biopsicossocial do adolescente e pela falta de apoio social recebido para exercer a função de pai é comum na sociedade. Entretanto, em situações de amparo familiar e social, os adolescentes são capazes de enfrentar as adversidades, participar das práticas de cuidados e proporcionar uma interação responsiva ao bebê (Henn, 2011; Radtke, 2005). Neste sentido, este adolescente envolveu-se satisfatoriamente com seu bebê na medida em que encontrou uma rede social ampla que funcionou como apoio e referência na formação de sua identidade paterna e enfrentamento de dificuldades.

\section{Grupo de Amigos}

\section{Semelhanças}

Os adolescentes revelaram que o grupo de amigos após a paternidade foi constituído por pessoas mais velhas e que realizam atividades "mais caseiras, calmas". Este grupo representou suporte e apoio aos adolescentes. Resultados semelhantes são encontrados em outros estudos com pais adolescentes (Bueno et al., 2012; Hoga \& Reberte, 2009; Levandowski \& Piccinini, 2006; Venturini, 2010).

A inserção em um novo grupo de amigos representa uma oportunidade para o adolescente ter contato com pessoas que desempenham diferentes papéis e a oportunidade 
de ampliar sua rede social (mesossistema). $\mathrm{O}$ potencial desenvolvimental dos ambientes em um mesossistema é aumentado no caso em que as exigências de papel nos diferentes ambientes (novo grupo de amigos) são compatíveis (amigos que também são pais). Nesta perspectiva, os papéis, atividades e díades em que a pessoa se envolve nestes ambientes encorajam o desenvolvimento da confiança mútua, de uma orientação positiva e de um consenso de objetivos (Bronfenbrenner, 2002).

No que se refere às mudanças de atividades ("mais caseiras, calmas"), destaca-se o valor positivo da inserção de pessoas mais velhas no grupo de amigos do adolescente: a relação com amigos pertencentes a contextos diferentes entre si oferecem uma gama maior de atividades, papéis e relações dos quais o adolescente pode apropriar-se, aumentando seu repertório de habilidades, uma vez que os pares podem modelar comportamentos (Bronfenbrenner e Carvalho-Barreto, 2011). Os adolescentes deste estudo apresentaram a consciência de que os aspectos da vida social não se mantiveram como era antes do filho nascer e que, uma vez pai, o homem devia abdicar de algumas de suas atividades cotidianas para uma vivência mais responsável e madura. Este tipo de reconhecimento também ocorre em pais adultos (Gabriel \& Dias, 2011). Não foram encontradas particularidades neste eixo temático.

\section{Trabalho}

\section{Semelhanças}

Os adolescentes participantes do estudo acreditavam que a carga horária de trabalho limitava o tempo de convívio familiar e que as situações que geravam estresse/tensão influenciavam no humor, afetando suas relações interpessoais familiares. Um estudo de revisão sistemática da literatura desenvolvido por Jager e Dias (2012a) apontou que o trabalho e o tempo disponível para a relação com a criança são importantes variáveis investigadas pelos estudos que buscam investigar a relação pai-bebê (Jager \& Dias, 2012b).
O local e as relações estabelecidas no trabalho constituem outro importante microssistema para o adolescente. Na medida em que as relações desenvolvidas neste microssistema afetam as relações desenvolvidas no microssistema familiar, o local de trabalho assume uma função de mesossistema, influenciando consideravelmente o desenvolvimento humano do indivíduo (Bronfenbrenner, 2002; Bronfenbrenner e Carvalho-Barreto, 2011). As condições de trabalho apareceram como fortes elementos capazes de influenciar a vivência da paternidade, uma vez que interferiram na disponibilidade parental e no tempo para o convívio familiar. Assim, algumas condições de trabalho podem afetar a capacidade dos pais de funcionarem em seu papel parental (Bronfenbrenner, 2002; Bronfenbrenner e Carvalho-Barreto, 2011). Entretanto, este ambiente pode minimizar os impactos das condições de trabalho no ambiente familiar quando oferece flexibilidade e relações positivas (apoio e confiança mútua), (Bronfenbrenner, 2002; Bronfenbrenner e Carvalho-Barreto, 2011). Isto pode observado no caso 3 descrito neste estudo, no qual o ambiente de trabalho representou para o adolescente uma importante rede de apoio no enfrentamento de dificuldades.

Embora o trabalho limite o tempo de convívio e influencie nas relações familiares dos adolescentes, ele oferece condições financeiras que aumenta a segurança no desempenho do papel familiar: pai-provedor. Principalmente para os homens, o trabalho representa um caminho para a realização pessoal e para o cumprimento de responsabilidades masculinas definidas em um nível macrossistêmico (cultura, adoção de práticas e políticas públicas que favoreçam a vida familiar) (Bronfenbrenner, 2002; Bronfenbrenner e Carvalho-Barreto, 2011). As responsabilidades masculinas predominantemente financeiras, cumpridas por intermédio do trabalho, também aparecem em estudos com pais adultos (Freitas et al., 2009; Piccinini et al., 2004) e adolescentes (Cabral, 2002; Paula, Bittar, Silva, \& Cano, 2010; Hoga \& Reberte, 2009). 
Principalmente nas classes populares, o trabalho e, consequentemente, o sustento familiar é uma maneira de obter uma identidade social legítima e ser reconhecido socialmente como adulto e responsável (Cabral, 2002). Estes aspectos puderam ser observados neste estudo, evidenciando que os adolescentes assumiram uma postura responsável frente à paternidade e à sua responsabilidade de provedor. Isto mostra que os pais adolescentes enfrentam desafios semelhantes aos de pais adultos (Levandowski \& Piccinini, 2006). Não foram encontradas particularidades neste eixo temático.

\section{Considerações Finais}

A análise longitudinal dos casos permitiu identificar diferenças na maneira de os adolescentes perceberem a paternidade logo após o nascimento do bebê e aos seis meses de vida da criança. Com o passar dos meses, embora os adolescentes ainda percebessem a vivência da paternidade como imprópria para a idade, eles reconhecerem um amadurecimento e crescimento pessoal por intermédio do aumento de responsabilidades e alterações na rotina familiar e social. Aos seis meses, os adolescentes já reconheciam mais facilmente suas responsabilidades de provedor e as responsabilidades ligadas ao cuidado do bebê. Eles revelaram a importância do apoio da família (pais), dos amigos e do trabalho na vivência da paternidade (desempenho do papel parental) e no enfrentamento das responsabilidades paternas. Nos dois períodos investigados também se destacou a noção de responsabilidade paterna direcionada para a manutenção econômica da família e a responsabilidade materna direcionada para a função de cuidado. Isto reflete uma posição ainda tradicional das funções parentais. É possível que esta seja uma caracterização vinculada ao contexto social e econômico dos adolescentes, mas que pode aparecer também em outras classes sociais.

Estes resultados evidenciam a importância do reconhecimento do nível e da qualidade do apoio familiar e social recebido, das características contextuais e dos padrões de relações estabelecidas em diferentes ambientes dos quais o adolescente faz parte. Este reconhecimento pode direcionar focos de ações capazes de oferecer maior segurança aos adolescentes no desempenho do papel parental, aumentando as possibilidades de o adolescente construir sua identidade paterna e fortalecer seus vínculos afetivos na nova família que se forma.

Este estudo não esgota as discussões sobre paternidade adolescente, uma vez que discute somente alguns aspectos que perpassam essa experiência. Entre as limitações, destacam-se: o reduzido número de participantes, que não permitiu a projeção dos resultados e comparação entre grupos de adolescentes com características contextuais distintas; e o roteiro da entrevista semiestruturada que pode não ter sido suficientemente sensível para captar de modo mais abrangente as opiniões e pensamentos dos adolescentes. Entretanto, a utilização de um roteiro semiestruturado pode ser útil na medida em atende o propósito de investigação de objetivos específicos do estudo e oferece um direcionamento para a análise.

Sugerem-se estudos comparativos entre pais adolescentes e adultos, que coabitem ou não com a mãe do bebê, com diferentes níveis de escolaridade, classes sociais e contextos culturais. Isto torna possível uma comparação entre grupos e uma melhor identificação de como aspectos contextuais podem interferir na vivência da paternidade durante a adolescência. Estudos que utilizem um instrumento de coleta de informações mais amplo podem oportunizar aos pais adolescentes uma fala livre e descolada de direcionamentos específicos. Ainda, parece interessante a realização de estudos que investiguem o engajamento parental nos cuidados com o bebê, a satisfação da relação/interação com o bebê e como os aspectos das relações sociais, crenças e práticas culturais dos jovens pobres podem revelar vulnerabilidades e particularidades específicas para a vivência da paternidade adolescente nesse contexto social. 


\section{Márcia Elisa Jager}

Mestre pela Universidade Federal de Santa Maria, Santa Maria - RS. Brasil.

Email: marciajager@yahoo.com.br

\section{Ana Cristina Garcia Dias}

Docente da Universidade Federal de Santa Maria, Santa Maria - RS. Brasil.

E-mail: anacristinagarciadias@gmail.com

Endereço para envio de correspondência:

Rua Venâncio Aires, 641, apto 102. Bairro Centro 97010-001. Santa Maria - RS. Brasil.

Recebido: 25/03/2014, $1^{a}$ Reformulação: 29/12/2014, Aprovado: 20/03/2015. 
Anstey, K. J., \& Hofer, S. M. (2004). Longitudinal designs, methods and analysis in psychiatric research. Australian in New Zealand Journal of Psychiatry. 38(3), 93-104.

Bardin, L. (2006). Análise de conteúdo. São Paulo, SP: Edições 70.

Bornholdt, E. A., Wagner, A., \& Staudt, A. C. P. (2007). A vivência da gravidez do primeiro filho à luz da perspectiva paterna. Psicologia Clínica, 19(1), 75-92.

Boulding, E. (1981). Las Mujeres y la violencia. In A. Joxe (Ed.), La violencia y sus causas (pp 265-279). Paris: Unesco,

Brazelton, T. B., \& Cramer, B. G. (2002). As primeiras relações (2a. ed.). São Paulo, SP: Martins Fontes.

Bronfenbrenner, U. (2002). A ecologia do desenvolvimento humano: experimentos naturais e planejados. Porto Alegrers: Artes Médicas.

Bronfenbrenner, U., \& Carvalho-Barreto, A. (2011). Bioecologia do desenvolvimento humano: tornando os seres humanos mais humanos. Porto Alegre, RS: Artmed.

Bronfenbrenner, U., \& Morris, P. A. (1998). The ecology of developmental processes. In: W. Damon., \& R. M. Lerner (Orgs.), Handbook of child psychology (Vol. 1: Theoretical models ofhuman development. pp. 9931028) New York, NY: John Wiley.

Bueno, M. E. N., Meincke, S. M. K., Schwartz, E., Soares, M. C., \& Corrêa, A. C. L. (2012). Paternidade na adolescência: a família como rede social de apoio. Texto e Contexto Enfermagem, 21(2), 313-319.

Bustamente, V. (2005). Ser pai no subúrbio ferroviário: um estudo de caso com homens de camadas populares. Psicologia em Estudo. Maringá. 10(3), 393-402.

Cabral, C. S. (2002). Vicitudes da gravidez na adolescência entre jovens de camadas populares do Rio de Janeiro. Dissertação de Mestrado, Instituto de Medicina Social, UERJ, Rio de Janeiro, RJ.

Carvalho, G. M., Merighi, M. A. B. \& Jesus, M. C. P. (2009). Recorrência da parentalidade na adolescência na perspectiva dos sujeitos envolvidos. Texto Contexto Enfermagem. 18(1), 17-24.

Costa, M. C. O, Lima, I. C., Martins Júnior, D. F., Santos, A. S. T., Araújo, F. P. O., \& Assis, D. R. (2005). Gravidez na adolescência e co-responsabilidade paterna: trajetória sócio-demográfica e atitudes com a gestação e com a criança. Ciência e Saúde Coletiva, 10(3), 719-727.

Dias, A. B., \& Aquino, E. M. L. (2006). Maternidade e paternidade na adolescência: algumas constatações em três cidades do Brasil. Cadernos de Saúde Pública. 22(7), 1447-1458.

Freitas, W. M. F., Silva, A.T.M.C., Coelho, E.A.C., Guedes, R.N., Lucena, K.D.T., \& Costa. A.P.T. (2009). Paternidade: responsabilidade social do homem no papel de provedor. Revista de Saúde Pública, 43(1), 85-90.

Gabriel M. R., \& Dias, A. C. G. (2011). A experiência da paternidade: como os homens se percebem como pais? In E. R. Goetz, \& E. C. Manfroi, Ele e ela grávidos (pp. 105-131). Curitiba, PR: Juruá.

Gomes, S. M. T. A. (2006). Maternidade e paternidade responsáveis na adolescência. Adolescência e Saúde. 3(3), 11-17.

Gonçalves, H., \& Knauth, D. R. (2006). Aproveitar a vida, juventude e gravidez. Revista de Antropologia, 49, 625-643.

Gontijo, D. T., \& Medeiros, M. (2008). "Tava morta e revivi": significado da maternidade para adolescentes com experiência de vida nas ruas. Cadernos de Saúde Pública, 23(2), 469-472.

Heilborn, M. L. (2006). Experiências da sexualidade, reprodução e trajetórias biográficas juvenis. In: M. L. Heilborn, E. M. L. Aquino, M. Bozon, D. R. Knauth (Eds.), O aprendizado da sexualidade: reprodução e trajetórias sociais de jovens brasileiros. Rio de Janeiro, RJ: Garamond.

Heilborn, M. L., \& Cabral, C. S. (2006). Parentalidade juvenil: transição condensada para a vida adulta. In A. A. Camaran (Org.), Transição para a vida adulta ou vida adulta em transição? (pp. 225-255). Rio de Janeiro, RJ: IPEA. 
Hardy, E. (2007). Vulnerabilidade de gênero para paternidade em homens adolescentes. Revista de Saúde Pública, 41(4), 565-572.

Henn, C. G. (2011). A experiência e a prática da paternidade na adolescência: Estudo longitudinal da gestação ao segundo ano de vida do bebê. Tese de Doutorado, Universidade do Rio Grande do Sul. Porto Alegre, RS, Brasil.

Hoga, L. A. K.; Reberte, L. M. (2009). Vivencias de la paternidad en la adolescencia en una comunidad brasileña de baja renta. Revista da Escola de Enfermagem - USP, 43(1), 110-116.

Jager, M. E., \& Dias, A. C. G. D. (2012a). Paternidade adolescente e a relação paibebê no primeiro ano de vida da criança. (Projeto de Pesquisa). Programa de PósGraduação em Psicologia, Universidade Federal de Santa Maria. Santa Maria, RS.

Jager, M. E., \& Dias, A. C. G. (2012b). A relação pai-filho: uma revisão sistemática da literatura nacional. In Anais do III Congresso Brasileiro de Psicologia da Saúde (pp. 285296). Santa Maria, RS.

Lamb, M.E. (1997). The role of the father in child development. New York, NY: John Wiley \& Sons.

Lamb, M. E. \& Elster, A. B. (1985). Adolescent mother-infant-father relationships. Developmental Psychology, 21(5), 768-773.

Levandowski, D. C., \& Piccinini, C. A. (2006). Expectativas e sentimentos em relação à paternidade entre adolescentes e adultos. Psicologia: Teoria e Pesquisa. 22(1), 17-28.

Levandowski, D., Piccinini, C. A., \& Lopes, R. (2008). Maternidade adolescente. Estudos de Psicologia, 25(2), 251-263.

Meincke, S. M. K., Soares, M. C., Schwartz, E., Zilmmer, J. V., Bueno, M. E. N., Monteiro, R. F. C., Eidam, M., ... Lopes, A. C. C. (2011). Redes sociais de apoio à paternidade na adolescência: um estudo multicêntrico. Revista de Enfermagem e Saúde, 1(1), 33-38.

Neri, A. L. (2001). Paradigmas contemporâneos sobre o desenvolvimento humano em psicologia e em sociologia. In A. L. Neri (Ed.), Desenvolvimento e envelhecimento: perspectivas biológicas, psicológicas e sociológicas (pp. 11-37). Campinas, SP: Papirus.

Neri, M. C. (Coord). (2010). A nova classe média, o lado brilhante dos pobres. Rio de Janeiro, RJ: FVG.

Nogueira, M. J., Martins, A. M., Schall, V. T., \& Modena, C. M. (2011). Depois que você vira um pai...adolescentes diante da paternidade. Adolescência \& Saúde, 8(1), 28-34.

Orlandi, R., \&Toneli, M.J. F. (2008). Adolescência e paternidade: sobre os direitos de criar projetos e procriar. Psicologia em Estudo, 13(2), 317-326.

Parke, R. D. (1996). Fatherhood. Cambridge, MA: Harvard University Press.

Patias, N. D. Jager, M. E., Fiorin, P. C. \& Dias, A. C. G. (2011). Construção histórica social da adolescência: Implicações na percepção da gravidez na adolescência como um problema. Revista Contexto \& Saúde, 10(20), 205-214.

Patias, N. D. Jager, M. E., Fiorin, P. C. \& Dias, A. C. G. (2012). Gestações na adolescência: multiplicidade de experiências em uma Unidade Básica de Saúde de Santa Maria/ RS. Revista Internacional Interdisciplinar Interthesis, 9(1), 260-277.

Paula, E. R., Bittar, C. M., Silva, M. A. I., \& Cano, M. A. T. (2010). A paternidade na adolescência e seu significado entre jovens universitários que a vivenciaram. Revista Mineira de Ciências da Saúde, 2, 28-42.

Piccinini, C.A., Silva, M. R., Gonçalves, T. R., Lopes, R. S., \& Tudge, J. (2004). O envolvimento paterno durante a gestação. Psicologia: Reflexão e Crítica, 17(3), 303-314.

Radtke, F. M. (2005). Adolescência, paternidade e cuidados: o sentido que os adolescentes pais atribuem a sua participação nos cuidados do filho. Dissertação de Mestrado, Universidade Federal de Santa Catarina. Santa Catarina, SC, Brasil.

Ramires, V. R. R. (1997). O exercício da paternidade hoje. Rio de Janeiro, RJ: Record. 
Santos, A., \& Carvalho, C. V. (2006). Gravidez na adolescência: um estudo exploratório. Boletim de Psicologia, 56(125), 135-151.

Santos, C.A. C., \& Nogueira, K. T. (2009). Gravidez na adolescência: falta de informação? Adolescência \& Saúde, 6(1), 48-56.

Stake, R. E. (1994). Case studies. In: N, Denzin, \& Y. Lincoln (Coords.), Handbook of qualitative Research (pp. 236-247). London: Sage.

Strauss, A., \& Corbin, J. (2008). Pesquisa qualitativa: técnicas e procedimentos para o desenvolvimento da teoria fundamentada. (2a. ed., L. O. Rocha, trad.). Porto Alegre, RS: Artes Médicas.

Venturini, A.P.C. (2010). Paternidade adolescente e os projetos de vida na gestação do primeiro filho. Dissertação de Mestrado, Universidade Federal do Rio Grande do Sul. Porto Alegre, RS.

World Health Organization (WHO). Adolescent health \& development. Geneve: WHO. Recuperado em 22 de dezembro de 2013, de <http://www.searo.who.int/en/Section13/ Section 1245.htm> 